\title{
Diagnostic measures for severe acute malnutrition in Indian infants under 6 months of age: a secondary data analysis
}

Ranadip Chowdhury ${ }^{1 *}$ D, Nitika ${ }^{1}$, Tarun Shankar Choudhary' ${ }^{1}$ Sunita Taneja ${ }^{1}$, Jose Martines ${ }^{2}$, Nita Bhandari ${ }^{1}$ and Rajiv Bahl ${ }^{3}$

\begin{abstract}
Background: Weight for length $z$-score $(W L Z)<-3$ is currently used to define severe acute malnutrition (SAM) among infants. However, this approach has important limitations for infants younger than 6 months of age as WLZ cannot be calculated using WHO growth standards if infant length is $<45 \mathrm{~cm}$. Moreover, length for age $z$-score $(L A Z)$ and weight for length z-score (WLZ) are least reliable measures, with high chances of variation, and less chances of detecting undernutrition in under 6 months infants. The objective of the current analysis was to compare WLZ with WAZ and LAZ in a cohort of Indian infants in predicting the deaths between 6 weeks and 6 months of age.
\end{abstract}

Methods: The data was from an individually randomized trial conducted in slums of Delhi, India in which infants' weight and length were measured at 6 weeks of age (at the time of the first immunization visit). Vital status of the infants was documented from 6 weeks to 6 months of age. The sensitivity, specificity, positive and negative predictive values, and positive and negative likelihood ratios were calculated for WAZ $<-3, W L Z<-3$, and LAZ $<-3$ for deaths between 6 weeks and 6 months of age. The receiver operating characteristics curve was calculated for each of the above anthropometric indicators.

Results: For deaths occurring between 6 weeks to 6 months of age, the specificity ranged between 85.9-95.9\% for all three anthropometric indicators. However, the sensitivity was considerably higher for WAZ; it was $64.6 \%$ for $W A Z<-3,39.1 \%$ for $L A Z<-3$, and $25.0 \%$ for $W L Z<-3$. WAZ $<-3$ had higher area under curve $(0.75 ; 95 \%$ Cl: 0.68 , 0.82 ) and hence, better discriminated deaths between 6 weeks and 6 months of age than WLZ $<-3$. The adjusted relative risk (RR 10.6, 95\% CI 5.9, 18.9) and the population attributable fraction (PAF 57.9, 95\% Cl 38.8, 71.0\%) of mortality was highest for WAZ $<-3$.

Conclusions: We found WAZ $<-3$ at 6 weeks of age to be a better predictor of death in the 6 weeks to 6 months of life in comparison to $W L Z<-3$ and $L A Z<-3$ and propose that it should be considered to diagnose SAM in this age group.

Keywords: Severe acute malnutrition, Weight for length z-score, Weight for age z-score, Length for age z-score, Under 6-month infants, Mortality

\footnotetext{
* Correspondence: ranadip.chowdhury@sas.org.in

'Knowledge Integration and Translational Platform (KnIT) at Centre for Health Research and Development, Society for Applied Studies, 45, Kalu Sarai, New Delhi 110016, India

Full list of author information is available at the end of the article
}

(c) The Author(s). 2021 Open Access This article is licensed under a Creative Commons Attribution 4.0 International License, which permits use, sharing, adaptation, distribution and reproduction in any medium or format, as long as you give appropriate credit to the original author(s) and the source, provide a link to the Creative Commons licence, and indicate if changes were made. The images or other third party material in this article are included in the article's Creative Commons licence, unless indicated otherwise in a credit line to the material. If material is not included in the article's Creative Commons licence and your intended use is not permitted by statutory regulation or exceeds the permitted use, you will need to obtain permission directly from the copyright holder. To view a copy of this licence, visit http://creativecommons.org/licenses/by/4.0/ The Creative Commons Public Domain Dedication waiver (http://creativecommons.org/publicdomain/zero/1.0/) applies to the data made available in this article, unless otherwise stated in a credit line to the data. 


\section{Background}

The first 6 months of life are marked by rapid growth, and neurological development [1]. During this period, optimal nutrition is through exclusive breastfeeding [2]. However, studies have identified high rates of nonexclusively breast-fed infants in this age group. Suboptimal practices predispose infants to undernutrition or growth faltering [3-6]. In low- and middle-income countries, 3.8 million under 6 months infants are severely wasted by weight for length $\mathrm{z}$-score $(\mathrm{WLZ}<-3)$ [7]. Also, in India, the burden of severe wasting is quite high (14.8\%) among infants less than 6 months of age, as reported in the National family Health Survey-4 (NFHS4, 2015-16) [8]. Based on alarmingly high rates of severe wasting in this age group, WHO updated its severe acute malnutrition (SAM) guidelines including for under 6 months infants for the first time in 2013 [9].

Diagnosis and management of SAM in under 6 months infants deserves special attention to reduce the global burden of SAM in under-5 children [9]. For children in the age group $6-59$ months, $\mathrm{WLZ}<-3$ is one of the criteria used to identify SAM, and this criterion was set based on the high risk of mortality observed in children below in comparison to children above this cut-off [10]. Due to lack of high-quality evidence, the same definition i.e., WLZ <3 was suggested for infants under 6 months of age [9]. The use of WLZ criteria in infants less than 6 months has some limitations. Firstly, the WLZ cannot be calculated using the WHO 2006 growth standards if length of an infant is less than $45 \mathrm{~cm}$, WLZ cannot be measured in a proportion of preterm or small for gestational age infants [11, 12]. Secondly, an accurate measurement of length is difficult in community settings in small infants as they tend to be in knee-bent position [13, 14]. Thirdly, it has been shown in African settings, that anthropometric parameters using length i.e., length for age z-score (LAZ) and weight for length z-score (WLZ) are least reliable measures, with high chances of variation, and less chances of detecting undernutrition in under 6 months infants $[15,16]$. However, chances of measurement error are also high for hanging weighing scales due to lack of calibration, deviation from accurate measurement over time as the springs stretch out etc. [17]

Realizing the importance, the WHO and a recent Child Health and Nutrition Research Initiative prioritized establishing diagnostic criteria for SAM among under 6 months infants as one of the priority research questions $[10,18]$. Limited evidence on the association between anthropometric indicators and mortality among under 6 months infants is available from South Asia where the burden of SAM is higher compared to other parts of the world $[11,12]$.

We compared WLZ with WAZ and LAZ when measured at 6 weeks of age (at the time of first immunization) in predicting deaths between 6 weeks and 6 months of age, using data from an individually randomized trial conducted in the urban slums of Delhi, India.

\section{Methods \\ Study description}

The is a secondary data analysis from an individually randomized, double blinded placebo-controlled trial conducted during 1995-97 to assess the safety and benefits of maternal postpartum, and infant vitamin A supplementation administered with each of the three diphtheria-tetanus-pertussis (DPT) and poliomyelitis immunizations and with a fourth dose with measles immunization on vitamin A status, anthropometric indicators, and severe morbidity during infancy [19]. This was a multi-country trial conducted in, India, Ghana and Peru. In this analysis we have presented findings from the Indian cohort where 4000 mother-infant dyads were enrolled 18-28 days after childbirth, from two slums of Delhi, Dakshinpuri and Tigri. The details of the original study are described elsewhere [19].

\section{Anthropometry measurements}

The weights and lengths of infants were measured at the time of the first immunization scheduled at 6 weeks of age. Weights were measured using hanging spring scales accurate to $100 \mathrm{~g}$, calibrated daily [19]. Lengths were measured using rigid length boards with a sliding foot scale accurate to $1 \mathrm{~mm}$ [19]. The team was trained using standard operating procedures for all measurements. Retraining was done based on the feedback received through monitoring by supervisors. Inter and intra observer standardization exercises were done before initiation of the study and periodically during the study [20]. Length was measured in triplicate, and the median was used, while the weight was measured once. Information regarding vital status of the infants was collected through household visits, every 4 weeks.

For this analysis, an infant was included if the weight and length was measured within 2 weeks of the first scheduled immunization at 6 weeks of age.

\section{Statistical methods}

All the analyses were done using Stata 15.0 (Stata Corp, College Station, TX, USA). WAZ, WLZ, and LAZ scores were calculated using WHO standards [21] Infants with extreme anthropometric $\mathrm{z}$-score values (LAZ, and WAZ values $<-6$ and $>+6$, and WLZ values $<-5$ and $>+5$ ) were excluded from the analysis [22]. The sensitivity, specificity, positive and negative predictive values, and positive and negative likelihood ratios were calculated for $W A Z<-3, W L Z<-3$, and $L A Z<-3$ for deaths between 6 weeks and 6 months of age. The sensitivity was 
defined as the proportion of infants having z-scores $<-3$ at 6 weeks of age among those who died between 6 weeks to 6 months of age. Specificity was defined as the proportion of infants having z-scores $\geq-3$ at 6 weeks of age among those who survived between 6 weeks to 6 months of age. Positive predictive value (PPV) was defined as the proportion of infants who died between 6 weeks to 6 months of age among those had z scores $<-3$ at 6 weeks of age. Negative predictive value (NPV) was defined as proportion of infants who survived between 6 weeks to 6 months of age among those had $\mathrm{z}$ scores $\geq-3$ at 6 weeks of age. The positive likelihood ratio was calculated as sensitivity/ (1-specificity), and negative likelihood ratio as (1-sensitivity)/specificity.

The receiver operating characteristics ROC curve, an index of the test's ability to discriminate between true positives and true negatives was calculated for each of the above anthropometric indicators. "DIAGT" command in Stata 15.0 was used to estimate sensitivity, specificity, predictive values, likelihood ratios, and area under curve (AUC) of anthropometric indicators for deaths between 6 weeks and 6 months of age [23]. The AUC for WAZ, WLZ, and LAZ were compared using "roccomp" command in STATA [24]. Also, the cut-off of anthropometric indicators with maximum AUC for death between 6 weeks and 6 months was computed using "cutpt" command in STATA [25].
The generalized linear model (GLM) of the binomial family with log link function was used to estimate the relative risk (RR) for mortality between 6 weeks and 6 months of age, for each anthropometric indicator. The models were adjusted for the intervention groups and sex of the infants. The population-attributable fraction for each anthropometric indicator was calculated using "punaf" command in Stata [26].

\section{Results}

The current analysis was done on 3702 infants for WAZ, 3678 infants for WLZ, and 3684 infants for LAZ (Fig. 1). The mean (standard deviation; SD) age of infants at the time of anthropometric assessment was 42.6 (1.6) days. The prevalence of $\mathrm{WAZ}<-3, \mathrm{WLZ}<-3$, and $\mathrm{LAZ}<-3$ at the time of the first immunization were 14.7, 4.3, and $9.8 \%$ respectively (Table 1 ).

Figure 2 represents the ROC for WAZ, WLZ, and LAZ. The cut-offs with maximum AUC were - 3.15, 1.78, - 1.64 for WAZ (AUC: 0.76), WLZ (AUC: 0.69), and LAZ (AUC:0.69), respectively. AUC was significantly different $(p$ value $<0.001)$ between three anthropometric indicators.

Table 2 presents the diagnostic accuracy measures at “-3" cut-off for WAZ, WLZ, and LAZ. The sensitivity for deaths between 6 weeks and 6 months of age for

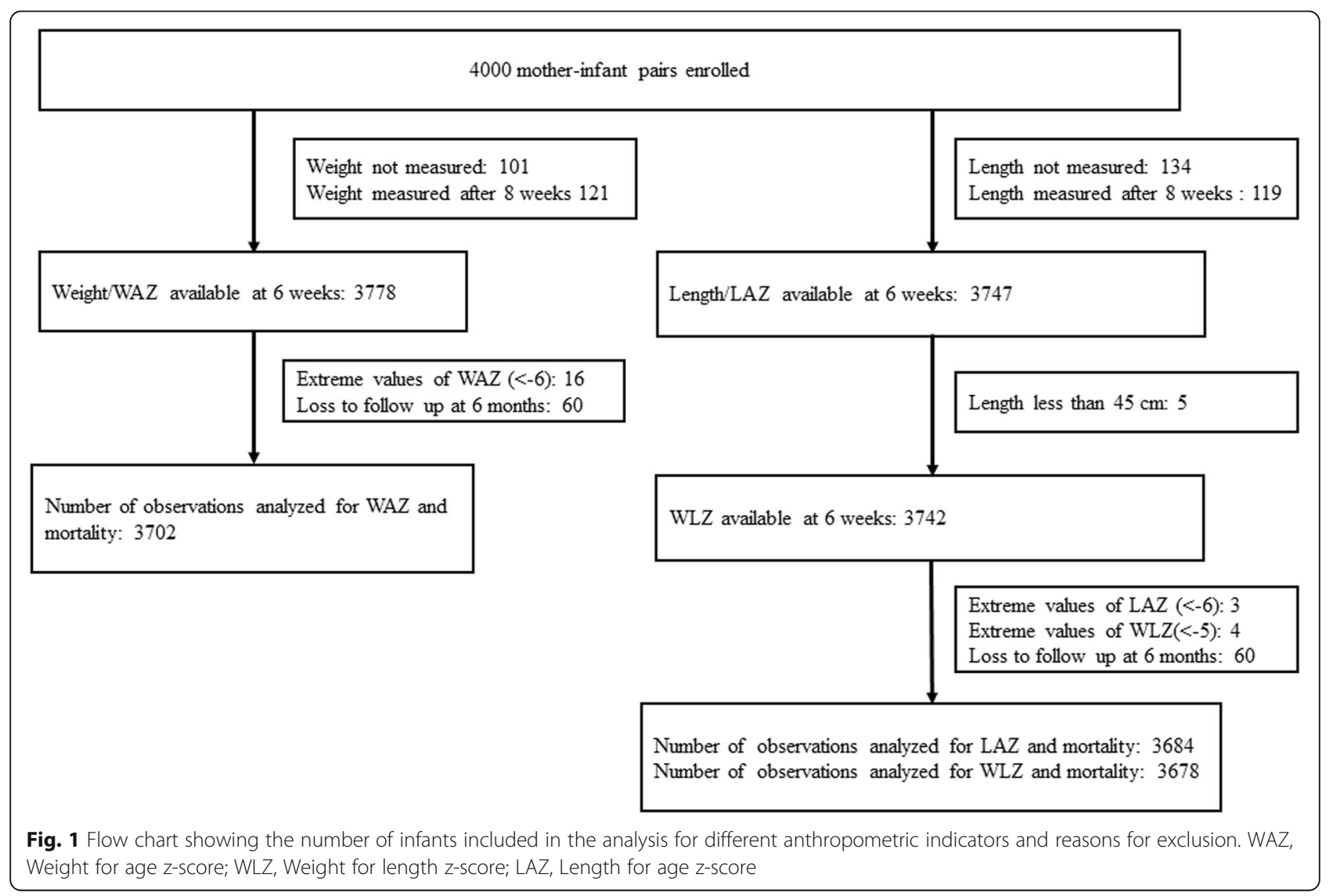


Table 1 Summary measures of anthropometric indicators

\begin{tabular}{llll}
\hline & $\begin{array}{l}\text { WAZ } \\
(\boldsymbol{n}=\mathbf{3 7 0 2})\end{array}$ & $\begin{array}{l}\text { WLZ } \\
(\boldsymbol{n}=\mathbf{3 6 7 8})\end{array}$ & $\begin{array}{l}\text { LAZ } \\
(\boldsymbol{n}=\mathbf{3 6 8 4})\end{array}$ \\
\hline Mean (SD) & $-1.83(1.16)$ & $-0.86(1.15)$ & $-1.41(1.18)$ \\
Prevalence of z-scores $<-3$ at 6 weeks $(95 \% \mathrm{Cl})$ & $14.7(13.5,15.9)$ & $4.3(3.7,5.0)$ & $9.8(8.9,10.8)$ \\
\hline
\end{tabular}

WAZ Weight for age z-score, WLZ Weight for length z-score, LAZ Length for age z-score.

$\mathrm{WAZ}<-3$ was $64.6 \%$, for $\mathrm{WLZ}<-3$ was $25.0 \%$, and for $\mathrm{LAZ}<-3$ was $39.1 \%$. The specificity ranged between 85 and $95 \%$ for all three indicators.

WAZ $<-3$ had higher AUC $(0.75 ; 95 \%$ confidence interval (CI): $0.68,0.82)$ compared to $W L Z<-3(0.60$; 95\% CI: $0.54,0.67)$ and $\mathrm{LAZ}<-3(0.65 ; 95 \% \mathrm{CI}: 0.58$, $0.72)$.

Table 3 presents the risk of death between 6 weeks and 6 months of age. The overall mortality rate from 6 weeks to 6 months of age was $1.3 \%$ (48 out of 3702). The mortality rate in $\mathrm{WAZ}<-3, \mathrm{WLZ}<-3$ and $\mathrm{LAZ}<-3$ groups were 5.7, 6.9 and 5\%, respectively. The adjusted relative risk for mortality was highest for $\mathrm{WAZ}<-3$ (10.6, 95\% CI: 5.9, 18.9). The population-attributable fraction for mortality was highest for infants with WAZ $<-3$ (57.9, 95\% CI: 38.8, 71.0\%).

\section{Discussion}

Our analysis showed that $\mathrm{WAZ}<-3$ has higher diagnostic accuracy to predict deaths between 6 weeks and 6 months in comparison to $\mathrm{WLZ}<-3$ or $\mathrm{LAZ}<-3$.
Similar to our findings, a community-based study conducted in Burkina Faso showed that infants with WAZ< -3 at 2 months of age had increased risk of mortality during infancy; this was not observed with $\mathrm{WLZ}<-3$ [11]. A study conducted in Kenya showed that WAZ measured in infants between 1 and 6 months of age was one of strongest predictors of inpatient and postdischarge mortality during infancy [12]. However, the study was done among hospitalized infants who had higher risk of mortality compared to community cohorts of healthy infants. Due to the higher sensitivity and AUC, use of $\mathrm{WAZ}<-3$ in comparison to $\mathrm{WLZ}<-3$, will detect larger proportions of infants at risk of death and have better discriminatory ability to distinguish between infants at risk of dying from those not at risk. For the community-based detection of SAM, WAZ is relatively easy and more efficient as it requires measuring only weights; these are usually measured during home visits and in immunization clinics and recorded on growth cards used in national programs. Considering the better diagnostic accuracy, and ease of use in community

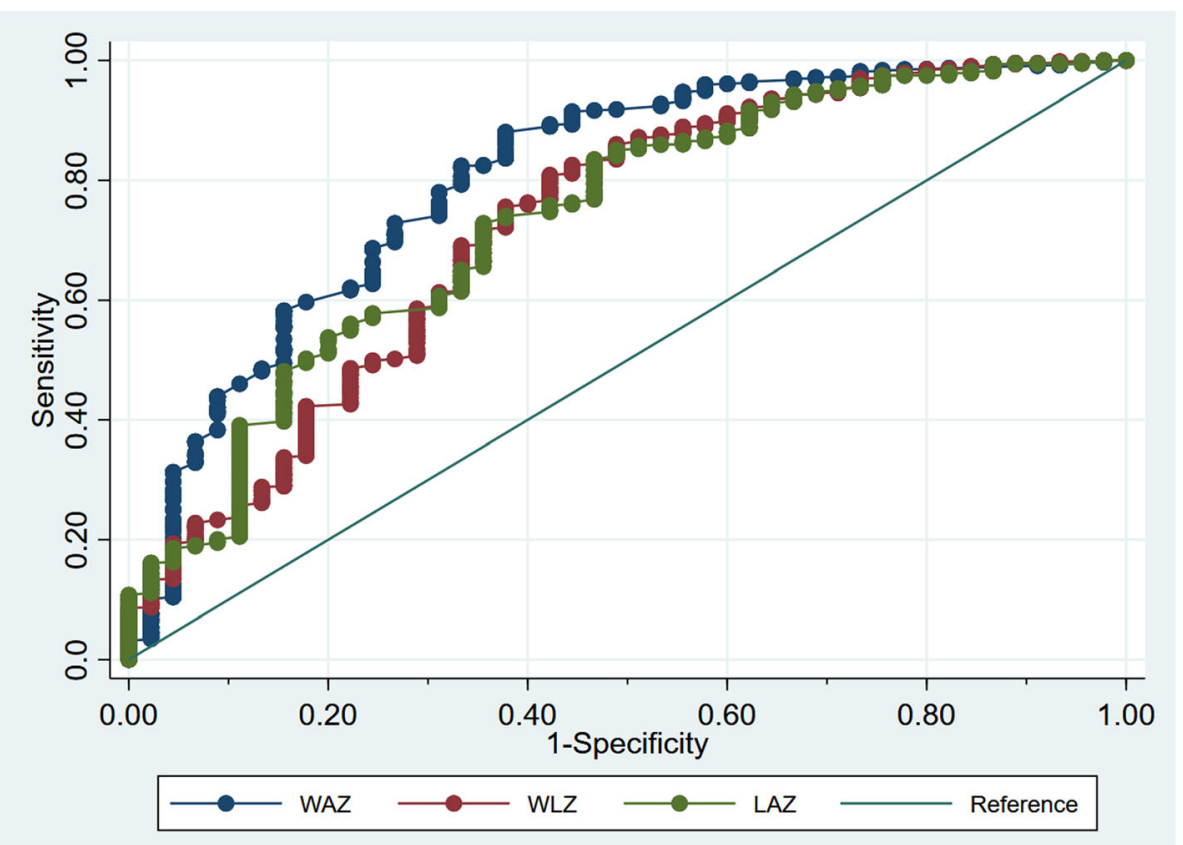

Fig. 2 Receiver operating characteristics curve for WAZ, WLZ, and LAZ and deaths between 6 weeks and 6 months. WAZ, Weight for age z-score; WLZ, Weight for length z-score; LAZ, Length for age z-score 
Table 2 Nutritional status at 6 weeks as a predictor of death between 6 weeks and 6 months of age

\begin{tabular}{|c|c|c|c|c|c|c|}
\hline $\begin{array}{l}\text { Nutritional Status at } 6 \\
\text { weeks }\end{array}$ & $\begin{array}{l}\text { Sensitivity } \\
(95 \% \mathrm{Cl})\end{array}$ & $\begin{array}{l}\text { Specificity } \\
(95 \% \mathrm{Cl})\end{array}$ & $\begin{array}{l}\text { Positive predictive } \\
\text { value } \\
(95 \% \mathrm{Cl})\end{array}$ & $\begin{array}{l}\text { Negative predictive } \\
\text { value } \\
(95 \% \mathrm{Cl})\end{array}$ & $\begin{array}{l}\text { Likelihood } \\
\text { Ratio+ } \\
(95 \% \mathrm{Cl}) \\
\end{array}$ & $\begin{array}{l}\text { Likelihood } \\
\text { Ratio- } \\
(95 \% \mathrm{Cl}) \\
\end{array}$ \\
\hline$W A Z<-3$ & $\begin{array}{l}64.6 \\
(49.5,77.8)\end{array}$ & $\begin{array}{l}85.9 \\
(84.8,87.0)\end{array}$ & $\begin{array}{l}5.7 \\
(3.9,7.9)\end{array}$ & $\begin{array}{l}99.5 \\
(99.1,99.7)\end{array}$ & $\begin{array}{l}4.6 \\
(3.7,5.8)\end{array}$ & $\begin{array}{l}0.4 \\
(0.3,0.6)\end{array}$ \\
\hline$W L Z<-3$ & $\begin{array}{l}25.0 \\
(13.2,40.3)\end{array}$ & $\begin{array}{l}95.9 \\
(95.2,96.5)\end{array}$ & $\begin{array}{l}6.9 \\
(3.5,12.0)\end{array}$ & $\begin{array}{l}99.1 \\
(98.7,99.4)\end{array}$ & $\begin{array}{l}6.1 \\
(3.6,10.5)\end{array}$ & $\begin{array}{l}0.8 \\
(0.6,0.9)\end{array}$ \\
\hline$L A Z<-3$ & $\begin{array}{l}39.1 \\
(25.1,54.6)\end{array}$ & $\begin{array}{l}90.6 \\
(89.6,91.5)\end{array}$ & $\begin{array}{l}5.0 \\
(2.9,7.8)\end{array}$ & $\begin{array}{l}99.2 \\
(98.8,99.4)\end{array}$ & $\begin{array}{l}4.2 \\
(2.9,6.1)\end{array}$ & $\begin{array}{l}0.7 \\
(0.5,0.8)\end{array}$ \\
\hline
\end{tabular}

WAZ Weight for age z-score, WLZ Weight for length z-score, LAZ Length for age z-score.

settings, we propose that $\mathrm{WAZ}<-3$ be considered for screening as well as diagnosis of SAM among under 6 months infants at the community and facility level.

It may be challenging to have different anthropometric screening criteria for infants younger than 6 months and for older infants and children. However, using WAZ for screening simplifies the assessment by relying on a single measurement (weight) and avoids depending on the measurement of lengths that is much harder to obtain in young infants. This challenge could be overcome through training of front-line health workers and medical officers [15]. Also, the use of WAZ criteria will lead to identification of increased number of SAM cases, as in this analysis we found that 14.7 and $4.3 \%$ infants were identified as SAM using the criteria of $\mathrm{WAZ}<-3$ and $\mathrm{WLZ}<-3$, respectively. And, if we translate this to around 27 million birth in a year in India, 3.90 million (14.7\%) will be identified as SAM using the criteria of $\mathrm{WAZ}<-3$ and 1.16 million (4.3\%) using $\mathrm{WLZ}<-3$. Thus, the use of $\mathrm{WAZ}<-3$ will lead to 2.7 million additional cases of SAM annually compared to if $W L Z<-3$ is used. This would require strengthening the health system in terms of inpatient and outpatient services for infants identified as SAM, as infants with any complications such as any serious medical or clinical condition, recent weight loss or failure to gain weight, ineffective feeding, pitting edema, and any medical or social issue would need a more detailed assessment, and even hospital admission [9].
Ideally, in a program setting, one would like to identify as many as possible infants who are at higher risk of death in the next few months, as a result of severe malnutrition. For this, using WAZ as a tool in households and community surveys will be appropriate. Length measurement at the treating facility could be a part of the further assessment of these severely malnourished infants.

The strengths of this analysis are the large numbers, weight and lengths measured by a standardized team and minimal loss to follow up (1.5\%). Some limitations are firstly, data used for analysis is around 20 years old. However, the relationship between anthropometric measures at 6 weeks and deaths between 6 weeks and 6 months observed, will be valid even today [12]. Secondly, we assessed diagnostic accuracy of anthropometric indicators assessed at 6 weeks of age, so we cannot comment on how anthropometric measures were associated with mortality in the first 6 weeks of life. Thirdly, we did not have information on weight and gestational age at birth.

\section{Conclusions}

We found that $\mathrm{WAZ}<-3$ is a better predictor of mortality between the ages of 6 weeks and 6 months compared to $W L Z<-3$ and $L A Z<-3$. These results support the consideration of using WAZ for screening and diagnosis of SAM in the first 6 months of life, as it will aid in identifying children at risk of mortality in the Indian subcontinent and similar settings. These findings should

Table 3 Nutritional status at 6 weeks and relative risk and population attributable fraction of mortality between 6 weeks and 6 months of age

\begin{tabular}{|c|c|c|c|c|c|}
\hline $\begin{array}{l}\text { Anthropometric indicators at } \\
6 \text { weeks of age }\end{array}$ & $\begin{array}{l}\text { Deaths among } \\
\text { malnourished (\%) }\end{array}$ & $\begin{array}{l}\text { Deaths among non- } \\
\text { malnourished (\%) }\end{array}$ & $\begin{array}{l}\text { Unadjusted } \\
\text { Relative Risk } \\
(95 \% \mathrm{Cl})\end{array}$ & $\begin{array}{l}\text { Adjusted } \\
\text { Relative Risk } \\
(95 \% \mathrm{Cl})\end{array}$ & $\begin{array}{l}\text { Population } \\
\text { Attributable fraction } \\
\% \\
(95 \% \mathrm{Cl})\end{array}$ \\
\hline WAZ & 31 of $545(5.7)$ & 17 of $3157(0.5)$ & $\begin{array}{l}10.6 \\
(5.9,18.9)\end{array}$ & $\begin{array}{l}10.6 \\
(5.9,18.9)\end{array}$ & $\begin{array}{l}57.9 \\
(38.8,71.0)\end{array}$ \\
\hline WLZ & 11 of 159 (6.9) & 33 of $3519(0.9)$ & $\begin{array}{l}7.4 \\
(3.8,14.3)\end{array}$ & $\begin{array}{l}7.3 \\
(3.8,14.2)\end{array}$ & $\begin{array}{l}21.6 \\
(7.5,33.6)\end{array}$ \\
\hline LAZ & 18 of $360(5)$ & 28 of $3324(0.8)$ & $\begin{array}{l}5.9 \\
(3.3,10.6)\end{array}$ & $\begin{array}{l}6.0 \\
(3.4,10.8)\end{array}$ & $\begin{array}{l}32.5 \\
(15.2,46.3)\end{array}$ \\
\hline
\end{tabular}

\footnotetext{
${ }^{a}$ Adjusted for intervention group and sex
} 
be confirmed through well-designed prospective studies for addressing the definition of SAM in infants $<6$ months of age in low- and middle-income countries (LMICs). Further, evaluation of MUAC for its role in screening of SAM in the first 6 months of life in Indian settings would allow policymakers to base decisions on all potential options.

\begin{abstract}
Abbreviations
AUC: Area under curve; Cl: Confidence interval; DPT: Diphtheria-TetanusPertussis; GLM: Generalized linear model; LAZ: Length for age z-score; LMICs: Low- and middle-income countries- LMICS; NFHS-4: National Family Health Survey-4; NPV: Negative predictive value; PAF: Population attributable fraction; PPV: Positive predictive value; ROC: Receiver operating characteristics; RR: Relative risk; SAM: Severe acute malnutrition; SD: Standard deviation; WAZ: Weight for age z-score; WLZ: Weight for length z-score
\end{abstract}

\section{Acknowledgements}

The Society for Applied Studies acknowledges the core support provided by the Department of Maternal, Newborn, Child and Adolescent Health, World Health Organization, Geneva (WHO Collaborating Centre IND-158); the Centre for Intervention Science in Maternal and Child Health (RCN Project No. 223269), Centre for International Health, University of Bergen (Norway); and Knowledge Integration and Translational Platform (KnIT), a Grand Challenges Initiative of the Biotechnology Industry Research Assistance Council (BIRAC), Department of Biotechnology, Government of India and Bill \& Melinda Gates Foundation (USA). The primary trial was supported by the Child Health and Development Division of WHO, the Johns Hopkins Family Health and Child Survival Cooperative Agreement (HRN 5986-A-00-6006-00) with funding from the United States Agency for International Development, and the Indian Council of Medical Research.

\section{Authors' contributions}

RC, N, TSC, ST, NB, RB conceptualized the study. RC, N, TSC, ST, RB developed the analytical strategy, performed the statistical analysis, interpreted the results. RC, TSC, N wrote the first draft of the manuscript. ST, JM, NB, RB reviewed the manuscript. All authors contributed to preparation and finalization of the manuscript, and all authors read and approved the final manuscript.

\section{Funding}

This work was supported by the Bill \& Melinda Gates Foundation, Grant Number OPP1055862. The funding agency has no role in the design of the study, the collection, analysis, and interpretation of data and in writing the manuscript.

\section{Availability of data and materials}

The data pertaining to the current analysis may be sent to the corresponding author, Ranadip Chowdhury (ranadip.chowdhury@sas.org.in).

\section{Declarations}

\section{Ethics approval and consent to participate}

The analysis was done based on anonymized data. The primary study was approved by the ethics committee of the All India Institute of Medical Sciences, New Delhi and WHO ethics review committee. The consent form for the primary study also sought written permission from parents to use the information for future research. All parents consented for the same.

\section{Consent for publication}

Not applicable.

\section{Competing interests}

The authors declare that they have no competing interests.

\section{Author details}

${ }^{1}$ Knowledge Integration and Translational Platform (KnIT) at Centre for Health Research and Development, Society for Applied Studies, 45, Kalu Sarai, New Delhi 110016, India. ${ }^{2}$ Centre for Intervention Science in Maternal and Child
Health, Centre for International Health, University of Bergen, Bergen, Norway. ${ }^{3}$ Department of Maternal, Newborn, Child and Adolescent Health and Ageing, World Health Organization, Geneva, Switzerland.

Received: 11 August 2020 Accepted: 24 March 2021

Published online: 01 April 2021

\section{References}

1. Johnson CP, Blasco PA. Infant growth and development. Pediatr Rev. 1997; 18(7):224-42. https://doi.org/10.1542/pir.18-7-224.

2. Kramer MS, Kakuma R. Optimal duration of exclusive breastfeeding. Cochrane Database Syst Rev. 2102;2012(8):CD003517.

3. Mwangome MK, Fegan G, Fulford T, Prentice AM, Berkley JA. Mid-upper arm circumference at age of routine infant vaccination to identify infants at elevated risk of death: a retrospective cohort study in the Gambia. Bull World Health Organ. 2012;90(12):887-94. https://doi.org/10.2471/BLT.12.1 09009.

4. Vygen SB, Roberfroid D, Captier V, Kolsteren P. Treatment of severe acute malnutrition in infants aged $<6$ months in Niger. J Pediatr. 2013;162(3):51521.e3.

5. Prendergast AJ, Humphrey JH. The stunting syndrome in developing countries. Paediatr Int Child Health. 2014;34(4):250-65. https://doi.org/10.11 79/2046905514Y.0000000158

6. Victora CG, Adair L, Fall C, Hallal PC, Martorell R, Richter L, et al. Maternal and child undernutrition: consequences for adult health and human capital. Lancet. 2008;371(9609):340-57. https://doi.org/10.1016/S0140-6736(07)61 692-4.

7. Kerac M, Blencowe H, Grijalva-Eternod C, McGrath M, Shoham J, Cole TJ, et al. Prevalence of wasting among under 6-month-old infants in developing countries and implications of new case definitions using WHO growth standards: a secondary data analysis. Arch Dis Child. 2011;96(11): 1008-13. https://doi.org/10.1136/adc.2010.191882.

8. Choudhary TS, Srivastava A, Chowdhury R, Taneja S, Bahl R, Martines J, et al. Severe wasting among Indian infants $<6$ months: findings from the National Family Health Survey 4. Matern Child Nutr. 2019;15(4):e12866.

9. WHO. WHO guidelines: updates on the management of severe acute malnutrition in infants and children: World Health Organization; 2013.

10. WHO/UNICEF. WHO child growth standards and the identification of severe acute malnutrition in infants and children: a joint statement by the World Health Organization and the United Nations Children's fund; 2009.

11. Mwangome M, Ngari M, Bwahere $P$, Kabore P, McGrath M, Kerac M, et al. Anthropometry at birth and at age of routine vaccination to predict mortality in the first year of life: a birth cohort study in BukinaFaso. PLoS One. 2019;14(3):e0213523. https://doi.org/10.1371/journal.pone.0213523.

12. Mwangome M, Ngari M, Fegan G, Mturi N, Shebe M, Bauni E, et al. Diagnostic criteria for severe acute malnutrition among infants aged under 6 mo. Am J Clin Nutr. 2017;105(6):1415-23. https://doi.org/10.3945/ajcn.11 6.149815.

13. Voss LD, Bailey BJ, Cumming K, Wilkin TJ, Betts PR. The reliability of height measurement (the Wessex growth study). Arch Dis Child. 1990;65(12):13404. https://doi.org/10.1136/adc.65.12.1340.

14. Mwangome M, Berkley J. Measuring infants aged below 6 months: experience from the field. Field Exchange. 2014;47:34.

15. Mwangome MK, Fegan G, Mbunya R, Prentice AM, Berkley JA. Reliability and accuracy of anthropometry performed by community health workers among infants under 6 months in rural Kenya. Trop Med Int Health. 2012; 17(5):622-9. https://doi.org/10.1111/j.1365-3156.2012.02959.x.

16. Mwangome MK, Berkley JA. The reliability of weight-for-length/height Z scores in children. Matern Child Nutr. 2014;10(4):474-80. https://doi.org/1 $0.1111 / \mathrm{mcn} .12124$.

17. Biehl A, Hovengen R, Meyer HE, Hjelmesaeth J, Meisfjord J, Grøholt E-K, et al. Impact of instrument error on the estimated prevalence of overweight and obesity in population-based surveys. BMC Public Health. 2013;13:146.

18. Angood C, McGrath M, Mehta S, Mwangome M, Lung'aho M, Roberfroid D, et al. Research priorities to improve the management of acute malnutrition in infants aged less than six months (MAMI). PLoS Med. 2015;12(4): e1001812. https://doi.org/10.1371/journal.pmed.1001812.

19. WHO/CHD immunisation-linked vitamin a supplementation study group. Randomised trial to assess benefits and safety of vitamin a supplementation linked to immunisation in early infancy. Lancet. 1998;352(9136):1257-63. 
20. Jelliffe DB. The assessment of the nutritional status of the community (with special reference to field surveys in developing regions of the world). Monogr Ser World Health Organ. 1966;53:3-271.

21. WHO. WHO child growth standards: length/height-for-age, weight-for-age, weight-for-length, weight-for-height and body mass index-for-age: methods and development; 2006.

22. WHO. WHO Anthro for personal computers manual: software for assessing growth and development of the world's children. Geneva: WHO; 2010

23. Seed PT, Tobias A. Summary statistics for diagnostic tests. Stata Tech Bull. 2001;10(59):90-3.

24. DeLong ER, DeLong DM, Clarke-Pearson DL. Comparing the areas under two or more correlated receiver operating characteristic curves: a nonparametric approach. Biometrics. 1988;44(3):837-45. https://doi.org/10.23 07/2531595

25. Fluss $R$, Faraggi $D$, Reiser $B$. Estimation of the Youden index and its associated cutoff point. Biom J. 2005;47(4):458-72. https://doi.org/10.1002/ bimj.200410135.

26. Brady AR. Adjusted population attributable fractions from logistic regression. Stata Tech Bull. 1998;7(42).

\section{Publisher's Note}

Springer Nature remains neutral with regard to jurisdictional claims in published maps and institutional affiliations.

Ready to submit your research? Choose BMC and benefit from:

- fast, convenient online submission

- thorough peer review by experienced researchers in your field

- rapid publication on acceptance

- support for research data, including large and complex data types

- gold Open Access which fosters wider collaboration and increased citations

- maximum visibility for your research: over $100 \mathrm{M}$ website views per year

At BMC, research is always in progress.

Learn more biomedcentral.com/submissions 